\title{
Estrutura e Autonomia Relativa: conceitos complementares
}

Jair Pinheiro ${ }^{1}$

Resumo: Este artigo visa examinar a relação de complementaridade entre os conceitos de estrutura e de autonomia relativa do Estado em Poder Político e Classes Sociais, de Nicos Poulantzas. Para alcançar este objetivo, procede-se à tarefa de definir tais conceitos, uma vez que se encontram apenas em estado prático na obra considerada.

Palavras-chave: estrutura. autonomia relativa. abstração real.

\begin{abstract}
This article aims to examine the complementary relationship between the structure and relative autonomy of the state in the work Nicos Poulantzas's Political power and social classes. Toward this object, one proceeds make the task of definition such concepts, considering that they are just in practice state in that work.
\end{abstract}

Keywords: structure. relative autonomy. real abstraction.

\section{Introdução}

Em 1968 Nicos Poulantzas publicou Poder Político e Classes Sociais (PPCS), que viria a tornar-se sua principal obra, tanto pelo impacto que teve na ciência política marxista como pelo debate que suscitou entre estudiosos filiados a outras tradições. Uma das características de interesse dessa obra é a adesão de Poulantzas à escola althusseriana e a consequente operacionalização das categorias, desenvolvidas por tal escola, no esforço de sistematizar a teoria do político no modo de produção capitalista como uma estrutura com autonomia relativa.

\footnotetext{
1 Professor do Depto. de Ciências Políticas e Econômicas da UNESP/Marília e pesquisador do NEILS - Núcleo de Estudos de Ideologias e Lutas Sociais e do grupo CPMT - Cultura e Política do Mundo do Trabalho. E-mail: pinheiroj@uol.com.br
} 
Esta adesão valeu a Poulantzas a extensão da crítica de determinismo estrutural (Miliband, 1975) dirigida a Althusser e seus discípulos. Curiosamente, parece ter passado despercebido ao escrutínio dos críticos que o conceito de autonomia relativa e de estrutura não são opostos nem alternativos, mas complementares. Se se toma os dois conceitos, separadamente e fora da teoria em que são desenvolvidos, tem-se a ideia de que a autonomia relativa seria uma espécie de atenuante da determinação estrutural, como parece ser o caso de Wright (1981).

Diferentemente do Prof. Décio Saes, que considera a autonomia relativa do Estado mais um tema que um conceito, porque "Para Poulantzas de Poder Político e Classes Sociais, a autonomia relativa do Estado não é um conceito; é, sim um tema geral, a ser explorado ao longo de todo o trabalho teórico. A esse respeito Poulantzas afirma: “(...) este termo autonomia' não deve ser tomado nas suas diversas aplicações, num sentido idêntico (...), ele serve aqui sobretudo para detectar os problemas. ${ }^{2 \prime \prime}$, (Saes, 1998a, p. 52); neste breve ensaio, desenvolverei o argumento de que, justamente os problemas que detecta, ligados à relação entre a estrutura jurídico-política e a econômica, exigem que se dê à noção de autonomia relativa um tratamento conceitual, o que é de grande proveito para uma sociologia política marxista.

Além desse tratamento - digamos - temático, da autonomia relativa do Estado, Saes detecta em PPCS outra possibilidade, segundo a qual Poulantzas admitiria que “(...) um tratamento relativamente autônomo, dado às estruturas do modo de produção, apenas exprime de um modo adequado a autonomia real das instâncias na prática social total.", (p. 55) mas argumenta que de acordo com a matriz "prática" de PPCS, “(...) é difícil - para não dizer inviável - a conciliação teórica entre as ideias de autonomia e de interdependência, quando ambas são encaradas como características reais do relacionamento entre

${ }^{2}$ Cf. Nicos Poulantzas, Pouvoir Politique et Classes Sociales, 2 volumes, E. François Maspero, Paris, 1971, 2.ํvolume, p. 110. Citado como em Décio Saes.

\begin{tabular}{l|l}
\hline 72 & Estrutura e Autonomia Relativa:...
\end{tabular} 
os níveis da prática social total." (p. 56). Não é banal para o meu argumento, que, nesta frase, a palavra "relativa" tenha sido suprimida, pois é justamente este caráter da autonomia que procuro demonstrar, o que pode ser alcançado desenvolvendo algumas noções e indicações encontradas em PPCS, sem desvirtuar o sentido geral da obra.

$\mathrm{Na}$ verdade, como ficará claro mais adiante, eu me apoio no excelente artigo do professor para extrair da leitura de Poulantzas uma conclusão diferente da dele quanto à autonomia relativa. Outra diferença que também deve ser assinalada, desde já, é que a despeito de tratar da autonomia relativa do Estado, Saes aborda um leque bastante amplo de questões, enquanto aqui me limito à relação entre estrutura e autonomia relativa no modo de produção capitalista (MPC), ou seja, nele se encontra um recorte longitudinal que procura dar conta das grandes linhas do desenvolvimento do processo histórico, aqui, encontra-se um recorte sociológico mais voltado para as questões gerais das práticas dos indivíduos-agentes enquanto suportes/portadores das estruturas e da função política do Estado.

Quanto ao método, cumpre informar que não me deterei no exame dos argumentos críticos, o que o leitor poderá buscar nos próprios autores; concentrarei meu esforço no exame da obra PPCS, apoiando-me em Saes e também em Althusser, com vistas a 1) extrair o que entendo serem os conceitos de estrutura e de autonomia relativa, por meio da explicitação de alguns pressupostos do argumento de Poulantzas e 2) justificar porque os concebo como complementares. Para isso, o ensaio dedica uma breve seção ao conceito de estrutura e, outra, mais extensa, ao conceito de autonomia relativa. Por fim, dado o limite de espaço, serei econômico nas citações de $P P C S$, o que pode ser uma dificuldade ao leitor não familiarizado com a obra.

\section{Estrutura}

Muita confusão se criou em torno do termo estrutura, uma vez que ele aparece em diferentes teorias sociais. Os críticos da 
teoria althusseriana tratam o termo como se palavra e conceito se identificassem imediatamente, de modo que o uso da palavra estrutura inviabilizaria o tratamento teórico da questão. Entre nós, Coutinho (2010) deu sua grande contribuição para a confusão, filiando Althusser ao estruturalismo da década de 1960, tradição que ele nunca reivindicou ${ }^{3}$, ao mesmo tempo ignorando a filiação a Espinosa, que ele reivindicava. Entretanto, como observa Saes (1998), os althusserianos operaram com o conceito sem defini-lo sistematicamente e, para preencher esta lacuna, Saes se apoia na assertiva de Poulantzas de que as instituições do Estado se assentam num conjunto de "valores" que

(...) reveste não simplesmente um papel ideológico de justificação, mas a função de uma condição de possibilidade das estruturas objetivas do Estado representativo moderno; estruturas que constituem as condições de possibilidade das coordenadas da base de uma sociedade capitalista cambista: são os valores "universais" de liberdade e igualdade formais e abstratos." (Poulantzas, 1965, p. 873. Aspas e itálicos no original)

Baseado nesta assertiva, Saes define estrutura como “(...) um "conjunto particular de valores" que orienta um certo tipo de atividade social, fixando os limites (valorativos) dentro dos quais se desenvolvem as ações sociais desse tipo. Noutras palavras: a estrutura é um padrão valorativo seguido pelas práticas de um certo tipo." (1998, p. 25).

Embora esta definição avance no conhecimento do objeto, a meu ver ela é insuficiente quanto ao esclarecimento da passagem dos limites valorativos às práticas e às ações e, se descartamos a existência espiritual das ideias (Althusser, 2006), à materialidade de tais limites, uma vez que limites valorativos supõem uma matriz objetiva consti-

\footnotetext{
3 Filiar-se é diferente de interlocução, que Althusser manteve, sobretudo com a psicanálise. A este respeito ver Louis Althusser, Psychanalyse et sciences humaines: deux conférences, Paris,1996; e Pascal Gillot, Alhusser et la psychanalyse, Paris, PUF, 2009.
}

\begin{tabular}{l|l}
\hline 74 & Estrutura e Autonomia Relativa:...
\end{tabular} 
tuída tanto de representações significativas como de rituais materiais (Althusser, id.) através dos quais eles são produzidos e reproduzidos.

Como valor não é um conteúdo discreto, uma ideia que possa ser isolada e reconhecida em sua particularidade e diferença, mas uma ideia-guia que opera por articulação a outras como um roteiro de conduta, porque é o efeito ideológico de práticas rituais materiais; então os valores são estruturas de pensamento correspondentes a essas práticas institucionalizadas em aparelhos determinados. Por isso, sugiro a complementação dessa definição pelo conceito de habitus (Bourdieu, 2008), entendido como disposição adquirida por efeito dos esquemas perceptivos inscritos nas condições materiais de existência das classes sociais.

Antes de prosseguir, vale alertar que há, tanto em Poulantzas como em Althusser, uma oscilação terminológica que desautoriza certos usos do termo estrutura em nome deles, aliás, por isso é necessário dar um tratamento teórico ao termo para torná-lo um conceito. Esta oscilação terminológica consiste no fato de que o econômico, o jurídico-político e o ideológico são frequentemente referidos pelos termos instância, região, nível e, raramente, por estrutura. Este último termo aparece, frequentemente, como uma espécie de referência sintética ao conceito althusseriano de totalidade-estruturada-com-dominância, que designa o todo social constituído daquelas três instâncias ou, estruturas, como prefiro, mas agora como conceito que articula dialeticamente a forma do pensamento e a forma social.

Portanto, desde que tenhamos sempre em mente a que nos referimos, o termo estrutura pode ser utilizado para designar conceitualmente tanto o todo social como suas partes (o econômico, o jurídico-político e o ideológico), embora me pareça mais adequado restringir o termo estrutura à designação das partes e referir-se ao todo pelos conceitos de modo de produção, quando tratar-se do objeto formal-abstrato, e formação social quando tratar-se de uma sociedade historicamente determinada. 
Assim, o conceito de estrutura jurídico-política como “(...) um sistema articulado de quatro conceitos: direito capitalista, burocratismo, efeito de isolamento e efeito de representação da unidade." (Saes, 1998a, p. 51) remete a diferentes aparelhos com suas práticas rituais específicas que engendram os esquemas perceptivos que permitem aos indivíduos-agentes atuarem livremente, porque são suportes/portadores de tal estrutura.

Este conceito de estrutura jurídico-política supõe uma estrutura econômica correspondente, ou seja, um caso histórico particular do conjunto "produção, distribuição, intercâmbio e consumo".

No M.P.C., em contrapartida, assistimos a uma combinação de homologia entre a relação de propriedade e a relação de apropriação real. Esta homologia instaura-se graças à separação entre produtor direto e meios de produção na segunda relação - o que Marx 'designa como separação entre o produtor direto e as suas condições naturais de trabalho - e que intervém no estágio da grande indústria. É nomeadamente desta separação, a qual faz do próprio trabalhador um elemento do capital e do trabalho uma mercadoria, que decorre o caráter do econômico deste modo como processo de produção da mais-valia. Esta combinação determina uma autonomia específica do político e do econômico, que Marx apreende nas suas duas manifestações. (Poulantzas, 1977, p. 31/2)

Portanto, a combinação histórica particular do conjunto "produção, distribuição, intercâmbio e consumo" é determinada pela relação entre os proprietários dos meios de produção e os produtores diretos nas sociedades dividas em classes. No MPC, essa relação é caracterizada pela homologia entre a relação de propriedade e a relação de apropriação real.

Uma das implicações dessa homologia é dividir as relações entre proprietários e não proprietários dos meios de produção

\begin{tabular}{l|l}
\hline 76 & Estrutura e Autonomia Relativa:...
\end{tabular} 
(designadamente relações sociais de produção) em duas esferas operacionalmente distintas, mas que se pressupõem mutuamente: a esfera da circulação, onde ambos se encontram e firmam contrato livremente, e a da produção, onde o segundo segue o primeiro na condição de subordinado, por efeito do seu ato de vontade (Marx, 1988, 1. 1, cap. IV). Ora, o fato de serem esferas operacionalmente distintas e se pressuporem é a expressão de uma autonomia relativa determinada pelo entrelaçamento típico entre elas no MPC, promovido pelo direito igualitário - conceito da estrutura jurídico-política - como elemento articulador. O direito promove este entrelaçamento porque é através dele que os indivíduos-agentes se tornam personificação das categorias econômicas (Marx, 1988, 1. 1, cap. II).

Vejamos como Poulantzas caracteriza a autonomia relativa das instâncias especificamente no modo de produção capitalista. Apoiando-se em Marx e em Rosa Luxemburgo, Poulantzas sustenta que ela se manifesta como: a) não-intervenção do político (ou Estado) no processo de produção (este não precisando, no modo de produção capitalista, da intervenção de "fatores extraeconômicos" - como a coerção militar estatal - para funcionar); b) não-intervenção do político (ou Estado) na reprodução ampliada das relações de produção (já que tal reprodução é determinada, não por objetivos políticos - estatais -, e sim, por “objetivos econômicos", isto é, a produção de mais-valia). ${ }^{4}$ (Saes, 1998a, p. 57)

Saes observa argutamente que, neste ponto, Poulantzas passa insensivelmente (termo utilizado por Saes) do nível de análise Estado como Estrutura para o do Estado como instituição. No primeiro caso, as relações entre as instâncias são de entrelaçamento entre elas

${ }^{4}$ Cf. Nicos Poulantzas, Pouvoir politique et classes sociales. cit., $1^{\circ}$ volume, p. 28 . Citado conforme Saes. 
e, no segundo, de não intervenção do aparato do Estado no aparato econômico. Precisamente no encontro desses dois níveis de análise se encontra a função política de ordem do Estado em

diversas modalidades que se referem aos níveis sobre os quais ela se exerce em articular: função técnico-econômica - nível econômico; função propriamente política - nível da luta política de classes; função ideológica - nível ideológico. A função técnicoeconômica e a função ideológica do Estado são, entretanto, sobredeterminadas pela sua função propriamente política - a que diz respeito à luta política de classes -, na medida em que constituem modalidades do papel global do Estado, fator de coesão da unidade de uma formação: este papel global do Estado é um papel político.", (Poulantzas, 1977, p. 48).

Tendo em vista que a articulação desses dois níveis de análise corresponde ao problema real da prática política, deixo em suspenso provisoriamente a questão da não-intervenção e passo a desenvolver meu argumento em favor de tomar a autonomia relativa como um conceito que designa um objeto determinado no interior da teoria do modo de produção como totalidade-estruturada-com-dominância, na próxima seção.

\section{Autonomia relativa}

Como já antecipado, o Prof. Décio Saes considera que a autonomia relativa d o Estado é uma exigência de ordem epistemológica, que não procede o postulado de Poulantzas de que essa autonomia seja real. Saes (1994) sugere alternativamente, apoiando-se em Balibar, o conceito de implicação recíproca entre as estruturas. Como Saes procede a um rigoroso exame das oscilações semânticas da expressão autonomia relativa em PPCS, e nada tenho a acrescentar quanto a isto, remeto o leitor ao seu artigo.

\begin{tabular}{l|l}
\hline 78 & Estrutura e Autonomia Relativa:...
\end{tabular} 
Entretanto, diferentemente de Saes, que interpreta essa oscilação como indicação de que a autonomia relativa é mais um tema que um conceito, sugiro interpretá-la como a lacuna de um conceito que opera em estado prático nas análises de PPCS. Este conceito em estado prático está subjacente às análises de Althusser e Poulantzas e, se explicitado, altera os termos da questão. Para encaminhar o argumento, sugiro que se tenha em mente que os indivíduos-agentes, enquanto suportes/ portadores das estruturas, podem se restringir à prática referida a uma das estruturas (econômica, jurídico-política ou ideológica), descomprometidos com as práticas relativas às demais estruturas, e muitos efetivamente assim se restringem. Embora não valha como demonstração teórica, este fato empiricamente demonstrável já é uma pista de que a autonomia relativa das estruturas é real.

O Estado, enquanto instituição, diferentemente dos indivíduosagentes, devidoà sua funçãogeral deordem, de coesão social desdobrada nas suas modalidades técnico-econômica, ideológica e política, tem de considerar as três estruturas em sua prática. Como por prática, em sintonia com Althusser (1964), Poulantzas entende o trabalho de transformação de uma matéria em um produto determinado, servindose dos meios adequados. Esta prática global do Estado consiste em transformar o antagonismo de classe em coesão social, reconhecida como legítima pela representação do povo-nação. Para isso, o Estado instituição se serve dos instrumentos jurídico-administrativos próprios e, através dele, mobiliza valores e instrumentos próprios ao conjunto das estruturas. Aliás, esta transformação do antagonismo de classe em coesão social, levada a cabo pelo conjunto do pessoal do Estado, incluído o governo, dá sustentação à assertiva de Poulantzas de que a função técnico-econômica e a ideológica são sobredeterminadas pela função propriamente política. Para esclarecer esse ponto, passo ao exame da autonomia relativa.

Diferentemente de estrutura, o conceito de autonomia relativa empregado por Poulantzas se encontra em Althusser, embora numa formulação complexa que requer um trabalho teórico deesclarecimento. 
Pensamos que o conteúdo dessas diferentes práticas em sua estrutura própria, que é, em todos esses casos, a estrutura de uma produção; o que distingue entre elas essas diferentes estruturas, ou seja, a natureza diferente do objeto ao qual elas se aplicam, dos meios de produção e das relações sob as quais elas produzem (esses diferentes elementos e sua combinação Verbindung - evidentemente variam quando se passa da prática econômica à prática política, em seguida, à prática científica e à prática teórico-filosófica). Pensamos as relações de fundação e de articulação dessas diferentes práticas, umas com as outras, em seu grau de independência, seu tipo de autonomia "relativa", elas mesmas fixadas por seu tipo de dependência a respeito da prática "determinante em última instância", a prática econômica. (1996, p. 64-65)

Nesta formulação, as instâncias do modo de produção correspondem a práticas específicas, referidas a estruturas (instância, nível ou região, para Althusser) que têm uma autonomia relativa porque mantêm entre si uma relação de independência/dependência, o que passarei a denominar interdependência. Entretanto, Althusser não forneceu os termos dessa relação, que equivale à autonomia relativa.

Esta relação de interdependência pode ser concebida como uma determinação externa, um limite imposto pelas estruturas, umas sobre as outras, ou como uma determinação interna, isto é, que as estruturas se interpenetram umas às outras, de maneira que as práticas a elas referidas pressupõem umas às outras. A meu ver, essa segunda alternativa é a que está subjacente à análise do capital, desde a afirmação de que os indivíduos não são mais que personificação de categorias econômicas, passando por todas as referências ao direito e ao Estado na análise do processo de valorização do capital. Também está no horizonte de Althusser e, em estado prático em Poulantzas, embora sem dar-lhe um tratamento teórico sistemático.

$80 \quad$ Estrutura e Autonomia Relativa:... 
Então resta por explicar essa interpenetração das estruturas, ou seja, a interdependência. Nesta formulação de Althusser está implícito o elemento, porque, a meu ver, o conceito de implicação recíproca, longe de ser alternativo ao de autonomia relativa, o pressupõe. Tratemos, então, de explicitá-lo. Para que a explicitação se torne mais consistente, convém colocar a seguinte questão: por que as estruturas se implicam mutuamente? Uma resposta, a meu ver inadequada, como já ficou claro pelo exposto até aqui, é que elas constituem limites externos umas às outras. Essa resposta corre o risco de resvalar para a concepção de que as estruturas constituiriam essências que entrariam em contato, o que Poulantzas critica, na introdução de PPCS, oferecendo como alternativa o conceito de matriz de articulação.

Para Poulantzas,

O que, portanto, distingue um modo de produção de outro (e que por conseguinte especifica um modo de produção) é esta forma particular de articulação que os seus níveis apresentam entre si: é o que doravante designaremos pelo termo de matriz de um modo de produção. Por outras palavras, definir rigorosamente um modo de produção consiste em descobrir a forma particular como se reflete, no interior deste, a sua determinação em última instância pelo econômico, reflexão essa que delimita o índice de dominância e de sobredeterminação desse modo de produção. (1977, p. 14)

Antes de avançar no exame deste conceito de matriz de articulação proposto por Poulantzas, como alguns intérpretes postulam a tese de uma unidade complexa sem determinação (não hierarquizada), convém colocar a questão: em que se baseia a determinação em última instância, já que ela é postulada, mas não demonstrada? Essa questão merece respostas distintas para a problemática da transição entre modos de produção e para a da aplicação da determinação em última instância do econômico num modo particular. A meu ver, e restringin- 
do-me ao MPC, a resposta para essa questão reside no fato de que, nas análises de Marx, a produção (por consequência lógica e material, também a reprodução) é da ordem da necessidade, mas uma necessidade natural ${ }^{5}$ que se realiza sob uma forma histórico-social determinada, os modos de produção dominantes em formações sociais determinadas. Por outras palavras, o econômico se reflete necessariamente através da prática no jurídico-político e no ideológico, de modo que a prática, como um momento ${ }^{6}$ subjetivo já rotinizado, manipula os fatores de produção (insumos, instrumentos, meios de produção) conforme as categorias da estrutura jurídico-política e da ideológica. Enfim, de acordo com essa formulação, consiste nessa mediação necessária do econômico pelo jurídico-político e pelo ideológico a determinação em última instância do econômico.

Se as estruturas não constituem limites externos umas às outras, a alternativa é considerar que há um elemento comum (interno) a elas e que, por isso, as articula. Uma relação de determinação estrutural, porque são estruturas articuladas, segundo uma determinada matriz de articulação, como uma relação de interdependência, implica que as práticas referidas a cada estrutura toma as formas das demais estruturas como conteúdos instrumentais, segundo esse elemento comum. Noutras palavras, para que as relações jurídicas de propriedade e a relação de apropriação real no processo produtivo adquiram funcionalidade como orientadora da conduta de indivíduos-agentes localizados em lugares distintos e opostos nas relações sociais de produção, portanto, efeito do jurídico sobre o econômico, é necessário que ambos os lugares sejam representados como uma relação entre vontades privadas autônomas, consequentemente, vendedores e

${ }^{5}$ Por isso adquire estatuto de necessidade lógica na ordem do pensamento. Como o francês é o idioma de origem do althusserianismo, convém distinguir besoin e nécessité, a que me refiro.

${ }^{6} \mathrm{O}$ outro é a ação, que tratei em "Para uma teoria marxista da ação". In: Novos Rumos, n. ${ }^{\circ}$ 46, São Paulo, 2006.

\begin{tabular}{l|l}
\hline 82 & Estrutura e Autonomia Relativa:...
\end{tabular} 
compradores de força de trabalho (indivíduos-agentes da produção) se encontram enquanto tais. Assim sendo, sujeito de direito (categoria ideológica) e proprietário (categoria econômica) têm como conteúdo comum a "vontade privada autônoma" e, ambas, operam como representação ideológica de um indivíduo abstrato, sem referência ao pertencimento de classe, mas sustentado no pertencimento ao povonação, o cidadão (categoria jurídico-política).

Talvez pareça excessivo afirmar que a autonomia da vontade privada é um elemento comum às estruturas e as articula, posto que é uma categoria ideológica, mas este aparente exagero se desfaz se considerarmos que a abstração real (Marx, 1971) resultante do movimento das mercadorias referidas umas às outras como valor têm indivíduos-agentes como proprietários que as levam ao mercado, ou seja, o valor como resultado da abstração real entre as mercadorias corresponde à autonomia da vontade privada como resultado da abstração real entre indivíduos-agentes que, ao se confrontarem no mercado como proprietários, abstraem todos os seus demais atributos para atuarem como simples vontade privada autônoma.

Portanto, é uma categoria ideológica porque é a representação de um processo material, longe de ser uma criação da razão ou o desenvolvimento do espírito. Pachukanis (2017) critica os juristas burgueses justamente por inverterem essa relação, de modo que na ideologia jurídica burguesa o econômico aparece como um efeito externo da volição de indivíduos particulares, mas como são sujeitos determinados, a nenhum deles se pode atribuir o ordenamento jurídico, então, para o circuito se fechar é preciso pressupor um Sujeito central (Althusser, 2006) que medeia a relação entre eles. Nisso reside a tendência da ideologia jurídica burguesa de escapar rumo ao místico.

A autonomia relativa entre as estruturas significa que esta relação entre categorias (sujeito de direito, proprietário e cidadão) comporta certa oscilação institucional, sem que as estruturas sejam transformadas no seu caráter fundamental, porque regida pela autonomia da vontade privada elevada a princípio ordenador do Estado. Pela 
mesma razão a oscilação é determinada pela luta de classes ou, mais precisamente, pela correlação de força entre as classes, uma vez que tanto os indivíduos-agentes membros das classes dominadas como das dominantes buscam incluir seus interesses na agenda do Estado investidos no estatuto de cidadão. Claro que tudo isso supõe condições "normais" de funcionamento de um Estado burguês, mas não se deve descartar como objeto de análise duas possibilidades: 1) como Poulantzas mesmo adverte, o poder das classes dominantes extrapola o Estado instituição; 2) as lutas das classes dominadas podem ir além da reivindicação de incluir seus interesses imediatos (Wright, 1981) na agenda do Estado e propor tornarem-se elas mesmas dirigentes do Estado, situação em que ou a categoria cidadão é substituída por outra ou é redefinida. Essas possibilidades não serão examinadas aqui, indiquei-as apenas para evitar a suposição ingênua de que as instituições políticas constituem todo o espaço da luta política.

De qualquer modo, exemplo clássico dessa oscilação são os direitos trabalhistas, que vão da negação deles pelo liberalismo cru da Lei Chapelier à máxima afirmação pela socialdemocracia, no limite das relações sociais de produção capitalistas, mas também se observa oscilação quanto ao que cada Constituição estabelece como critério de pertencimento ao povo-nação, assim como quanto à aplicação do direito de propriedade, que comporta oscilação normativa quanto às suas faculdades (uso, gozo, disposição e reivindicação). Vale lembrar que Saes detecta e teoriza sobre essa oscilação, pelos menos no que se refere aos direitos sociais, sob o ângulo da ambivalência do direito igualitário na sua crítica aguda a Marshall (2000) e, sob o ângulo da defasagem entre as estruturas, no exame do desenvolvimento da cidadania no Brasil (2001).

Para concluir o artigo, embora sem esgotar o tema da relação de complementaridade entre os dois conceitos tomados como objeto, recorro ao conceito de efeito de isolamento e seu lugar na representação da unidade e nas políticas de Estado como produto da sua função política. O efeito de isolamento ocupa um lugar central na análise

$84 \quad$ Estrutura e Autonomia Relativa:... 
do político em PPCS, no entanto Poulantzas nada diz sobre a causa desse efeito, mas afirma enfaticamente que "Este efeito de isolamento é terrivelmente real, e tem um nome: a concorrência entre os operários assalariados e entre os capitalistas proprietários privados.", (p. $126-$ itálico no original), como se buscasse cobrir com a ênfase a lacuna de um conceito. $\mathrm{O}$ argumento que desenvolvi até aqui visou justamente oferecer o par conceitual da abstração real dos proprietários e da autonomia da vontade privada para cobrir tal lacuna. A esta solução teórica pode-se opor duas objeções: 1) em Poulantzas o efeito de isolamento é um efeito do jurídico sobre o econômico e 2) a abstração real dos proprietários não se aplica aos trabalhadores.

Quanto à primeira objeção, como já desenvolvido anteriormente, as categorias econômicas se refletem necessariamente na ideologia jurídica através da prática, de maneira que, no MPC consolidado e com o estabelecimento do ordenamento jurídico correspondente, a representação do econômico pela ideologia jurídica passa a operar como reguladora do processo econômico. Para contestar a segunda objeção, basta lembrar que é como proprietário da sua força de trabalho que os trabalhadores se confrontam com os capitalistas.

A representação do povo-nação é, na verdade, o efeito do jurídico sobre o político, uma espécie de efeito interno a uma estrutura que, embora dual, constitui uma unidade. Seria um tanto arbitrário admitirmos a eficácia do efeito de representação da unidade, se a representação fosse apenas uma ideia, não a representação de um processo de abstração real entre proprietários. Por esta via, a representação da unidade também é um efeito do econômico sobre o político, juridicamente mediado. Quando Poulantzas assinala que a ideologia jurídica é dominante na região do ideológico (tomando de empréstimo sua terminologia), ele deixa implícito como possibilidade a pesquisa da questão de como as demais ideologias (religiosa, nacional etc.) são incorporadas à representação do povo-nação pela função ideológica do Estado, que as articula à ideologia jurídica conforme a apropriação dessas ideologias pelas classes em luta (Almeida, 1995). 
O problema do não-intervencionismo está igualmente relacionado com a função política do Estado, de como essa função incide sobre a função técnico-econômica. Sobre o não-intervencionismo, Saes afirma que "É portanto admissível - feitas algumas pequenas concessões teóricas - sustentar que o aparelho estatal capitalista, ao manter recorrentemente o quadro ideológico e político que induz o produtor direto a prestar por sua livre e espontânea vontade sobretrabalho ao proprietário dos meios de produção, não está a rigor "intervindo" no aparelho econômico produtivo.", (1998a, p. 58). No entanto, como afirma Saes, o processo histórico de criação deste quadro exige uma prática intervencionista.

Entretanto, resta por incluir na análise a intervenção do jurídicopolítico no econômico como exigência da função política global de coesão social e da sua modalidade específica, a função técnicoeconômica. Essa inclusão não implicará analisar nenhum caso concreto ou a questão em toda sua extensão teórica, mas apenas indicar as linhas gerais da intervenção do jurídico-político no econômico pela função política do Estado conforme o conceito de autonomia relativa. Esta intervenção sempre ocorre, não diretamente no aparelho produtivo, mas através das políticas de Estado (tanto econômica como social), que podem conceder mais direitos aos trabalhadores e, com isso, reduzir o poder legiferante ${ }^{7}$ do capitalista sobre seu próprio negócio, ou inversamente. Do mesmo modo, as políticas fiscal, monetária, financeira etc. afetam os interesses das classes e frações que compõem o bloco no poder. Em qualquer caso, a elaboração de diferentes políticas de Estado combina, de diferentes maneiras, os limites das categorias sujeito de direito, proprietário e cidadão conforme a correlação de força entre as classes em luta. Portanto, a autonomia relativa do Estado pode ser definida genérica e sinteticamente como a possibilidade de elaboração de diferentes políticas de Estado no limite estabelecido

\footnotetext{
7 Por poder legiferante do capitalista entendo a capacidade de regular as distintas relações (com o trabalhador, consumidor e provedor) do seu negócio, estabelecendo normas técnicas, protocolos, obrigações etc. onde o Estado é omisso.
} 
pela intersecção da tríade categorial sujeito de direito, proprietário e cidadão no seu elemento comum: a autonomia da vontade privada.

\section{Referências Bibliográficas}

ALMEIDA, Lúcio Flávio de. Ideologia Nacional e Nacionalismo. São Paulo: Educ, 1995.

ALTHUSSER, Louis. Sobre a reprodução. Petrópolis: Vozes, 1999.

ALTHUSSER, Louis. Lire Le Capital. Paris: , 1996.

ALTHUSSER, Louis. Psychanalyse et Sciences Humaines. Deux Conférences. Paris: Librairie Générale Française/IMEC, 1996.

ALTHUSSER, Louis. Pour Marx. Paris: François Maspero, 1973.

BOURDIEU, Pierre. A distinção: crítica social do julgamento. São Paulo: Edusp, 2008.

COUTINHO, Carlos N. O estruturalismo e a miséria da razão. São Paulo: Expressão Popular, 2010.

GILLOT, Pascale. Althusser et la psychanalyse. Paris: Presses Universitaires de France, 2009.

MARX, Karl. O capital, L. 1, v. 1. São Paulo: Nova Cultural, 1988.

MARX, Karl. Contribuição para a crítica da economia política. Lisboa: Editorial Estampa, 1971. 
MILIBAND, Ralf. O Estado capitalista: resposta a Nicos Poulantzas. In: Debate sobre o Estado capitalista. Porto: Edições Afrontamento, 1975.

PACHUKANIS, Eviguiéni. Teoria geral do direito e marxismo. São Paulo: Boitempo, 2017.

PINHEIRO, Jair. "Para uma teoria marxista da ação". In: Novos Rumos, São Paulo: Instituto Astrojildo Pereira, n.ํ 46, 2006.

POUlANTZAS, Nicos. Poder Político e Classes Sociais. São Paulo: Martins Fontes: 1977.

POULANTZAS, Nicos. "Préliminaires à l'étude de l'hégémonie Dans l'État". In: Les Temps Modernes, Paris, n.ํ 234, novembre 1965.

SAES, Décio. História da Cidadania no Brasil. São Paulo: IEA/USP, 2001.

SAES, Décio. Cidadania e Capitalismo (uma abordagem teórica). São Paulo: IEA/USP, 2000.

SAES, Décio. "O impacto da teoria althusseriana da histórica na vida intelectual brasileira". In: MORAES, João Q. de (org.). História do marxismo no Brasil. V. III. Campinas: Edunicamp, 1998.

SAES, Décio. "A questão da autonomia relativa do Estado em Poulantzas". In: Crítica Marxista, São Paulo: Brasiliense, n. 7, 1998a.

SAES, Décio. "Marxismo e história". In: Crítica Marxista, São Paulo: Brasiliense, n. ${ }^{\mathrm{o}}$ 1, 1994.

WRIGHT, Eric O. Classe, Crise e o Estado. Rio de Janeiro: Zahar, 1981. 